\title{
Alobar Holoprosencephaly with Duodenal Atresia: A Case Report
}

\author{
Wiryawan Permadi, D. Setiawan, M. Alamsyah Aziz*, Yanuarman, Anita D. Anwar, \\ F. F. Wirakusumah
}

Obstetrics and Gynecology Department, Faculty of Medicine, Padjadjaran University, Hasan Sadikin Hospital, Bandung West Java, Indonesia

Email: *alamsya ha ziz9119@gmail.com

How to cite this paper: Permadi, W., Setiawan, D., Alamsyah Aziz, M., Yanuarman, Anwar, A.D. and Wirakusumah, F.F. (2019) Alobar Holoprosencephaly with Duodenal Atresia: A Case Report. Open Journal of Obstetrics and Gynecology, 9, 1189-1196.

https://doi.org/10.4236/ojog.2019.98115

Received: June 3, 2019

Accepted: August 18, 2019

Published: August 21, 2019

Copyright $\odot 2019$ by author(s) and Scientific Research Publishing Inc. This work is licensed under the Creative Commons Attribution International License (CC BY 4.0).

http://creativecommons.org/licenses/by/4.0/

\section{Abstract}

Introduction: Holoprosencephaly (HPE) is the most frequent malformation of the prosencephalon. It represents the absence or incomplete division of the prosencephalon during the $4^{\text {th }}$ and $8^{\text {th }}$ week of gestation. Its incidence is estimated to be 1 in 16,000 live births and 1 in 250 spontaneous abortions. According to the degree of cerebral involvements, it is classified into 3 types: alobar, semilobar, and lobar. Alobar is the most severe type. Duodenal atresia occurs in approximately 1:10,000 live births. It can be fatal unless diagnosed and surgically treated promptly. It is a less common cause of polyhydramnion. The diagnosis of duodenal obstruction may be suspected prior to the child's birth by prenatal ultrasonography. The outcome of congenital duodenal obstructions, in terms of mortality rate, has improved over the last decades, mainly attributable to the improvement in the quality of prenatal diagnosis and neonatal intensive care. Embryological basis for etiology of duodenal atresia is thought to be due to errors of recanalization. Duodenal atresia is associated with other congenital anomalies in spite with holoprosencephaly. This is the only case (HPE with duodenal atresia) which is reported in Hasan Sadikin Hospital in the last five years. Materials and Methods: A patient $\mathrm{G}_{2} \mathrm{P}_{1} \mathrm{~A}_{0}$ who had vaginal birth 6 years ago, without complication on mother and fetus was referred to Hasan Sadikin Hospital with abdominal discomfort as main complaint on her 33 - 34 weeks of pregnancy. Prenatal care was during the first and second trimester by midwife and sonography in satellite hospital. She had polyhydramnion and head abnormality and referred to Hasan Sadikin Hospital. Sonography examination showed alobar holoprosencephaly, abnormal facial (cleft lip and palate, absent nasal bone, hypotelorism), duodenal atresia and polyhydramnios (Amniotic Fluid Index $50 \mathrm{~cm}$ ); other examinations were normal. Amnioreduction and karyotyping examination were done. After 3 weeks the amniotic fluid increased (Amniotic 
Fluid Index $45 \mathrm{~cm}$ ) and the patient complaint recurrent abdominal discomfort, so second amnioreduction was done. Estimated fetal weight was 2500 gram, using Doppler examination umbilical arteries were in normal limits (pulsatility index $=1.08$ ). Cesarean section on 38 weeks of pregnancy was done considering the abnormal head circumference and diameter as requested by the mother and the family. Results: The patient had poor prenatal care, late diagnosed congenital anomalies i.e. holoprosencephaly, facial anomaly and duodenal atresia. Fetal malformation might be clearly visible earlier if sonography examination on the first and second trimester was done appropriately, and mother and family were informed to choose the right action. Postnatal examination (MRI and USG) were not done. BNO examination revealed double bubble on the upper abdomen up to the left and right part. The baby was referred to the pediatric surgery with duodenal atresia and duodenostomy was planned. Genetic testing using conventional karyotype analysis ruled out aneuploidy of chromosomes 13, 18, 21, X and Y. No other risk factors such as smoking, alcohol, diabetes, infectious disease and drugs were before and during pregnancy. But she had bad environmental condition near a river with colored and bad smelled water from factory waste. Conclusions: Alobar holoprosencephaly is a disorder of brain development with a very poor prognosis. Combination of alobar holoprosencephaly and duodenal atresia disorders is rare. It might be diagnosed early through appropriate prenatal care and ultrasound examination. The etiology of holoprosencephaly is variable, due to environmental, infection, teratogenic, and genetic factors. The parents should be informed since early about poor prognosis of holoprosencephaly and the best treatment or procedure to be chosen.

\section{Keywords}

Holoprosencephaly, Duodenal Atresia, Ultrasound Examination

\section{Introduction}

Holoprosencephaly (HPE) is the most frequent malformation of the prosencephalon. It represents the absence or incomplete division of the prosencephalon during the $4^{\text {th }}$ and $8^{\text {th }}$ weeks of gestation. The incidence is estimated to be 1 in 16,000 live births and 1 in 250 spontaneous abortions. It is classified in 3 types, according to the degree of cerebral involvement: alobar, semilobar, and lobar [1] [2] [3]. A series of facial anomalies are frequently associated, due to the common origin of embryonic forebrain and midface from prechordal mesoderm. Environment, mechanical and genetic factors were mentioned as possible causes, such factors including chromosome aneuploidy, structural abnormality, autosome recessive and dominant syndromes and maternal diabetes [4] [5]. The role of maternal and paternal ages, parental consanguinity, maternal smoking and drinking habits are controversial.

Duodenal atresia is a disorder in which the duodenum is obstructed by a seg- 
ment that has complete obliteration of the lumen. Duodenal atresia may occur as an isolated anomaly or in association with other anomalies. Approximately one-third of fetuses with duodenal atresia have trisomy 21 (30\%), and with anatomic malformation in about $50 \%$ cases including cardiac defects, cleft lip and palate and other digestive system anomalies, defect of the urinary and musculoskeletal systems. Duodenal atresia is the most common, but not the only cause of duodenal obstruction [6] [7].

This case is a rare example of the pregnancy output that has conditions as combination of alobar holoprosencephaly, abnormal facial, duodenal atresia and polyhydramnion. It is the only case (HPE with duodenal atresia) which is reported in Hasan Sadikin Hospital in the last five years.

\section{CASE}

A 27-year-old $\mathrm{G}_{2} \mathrm{P}_{1}$ Ao female was referred at $33^{\text {rd }}-34^{\text {th }}$ weeks gestation with abdominal discomfort as main complaint. Prenatal care on the first and second trimester was by a midwife. She was referred to a district hospital due to suspicious of abdominal overdistention. Sonography examination revealed polyhydramnion and abnormality of the fetus head. She was referred to Hasan Sadikin Hospital.

General physical examination was unremarkable. The Uterus was Gravid with symphysis-fundal height of $37 \mathrm{~cm}$. A singleton fetus was in cephalic presentation. The fetal heart sound was 140 beats per minute. The mother had no history of Diabetes Mellitus, hypertension or other chronic diseases. Her first pregnancy was born preterm female baby in Low birth weight (1800 gram) from spontaneous delivery with normal growth and development until present $6^{\text {th }}$ years old.

Fetomaternal sonographic examination revealed a single live fetus with some suggestive symptoms or signs of congenital malformation consists of alobar holoprosencephaly, duodenal atresia, labiopalatoschizis, and polyhydramnion. Axial sonograms of the fetal head (Figure 1 and Figure 2) showed dilated single cerebral ventricle, with no evidence of anterior midline echo (falx, inter hemispheric cistern and septum pellucidum). The thalami appeared relatively small and fused; with a thin midline, linear echoic septum separating them. It protrudes into the single ventricular cavity. The third ventricle was not visualized. The Spine and cranium appeared to be well formed. Biparietal diameter and head circumference were estimated gestational age of 39 - 40 weeks. Abdominal circumference and femur length were all consistent with the clinically estimated gestational age of 33 - 34 weeks. The interorbital distance was $1.3 \mathrm{~cm}$; with evidence of facial anomalies was noted sonographically. The amniotic fluid index was $50 \mathrm{~cm}$.

The first amnioreduction was $\pm 1500 \mathrm{cc}$, and karyotyping examination was done. Three weeks afterwards the patient complained abdominal discomfort (AFI $45 \mathrm{~cm}$ ) and second amnioreduction was $\pm 1200 \mathrm{cc}$. Cesarean section on 38 weeks pregnancy was done considering the abnormal head circumference and diameter as requested by the mother and the family. BNO examination revealed 


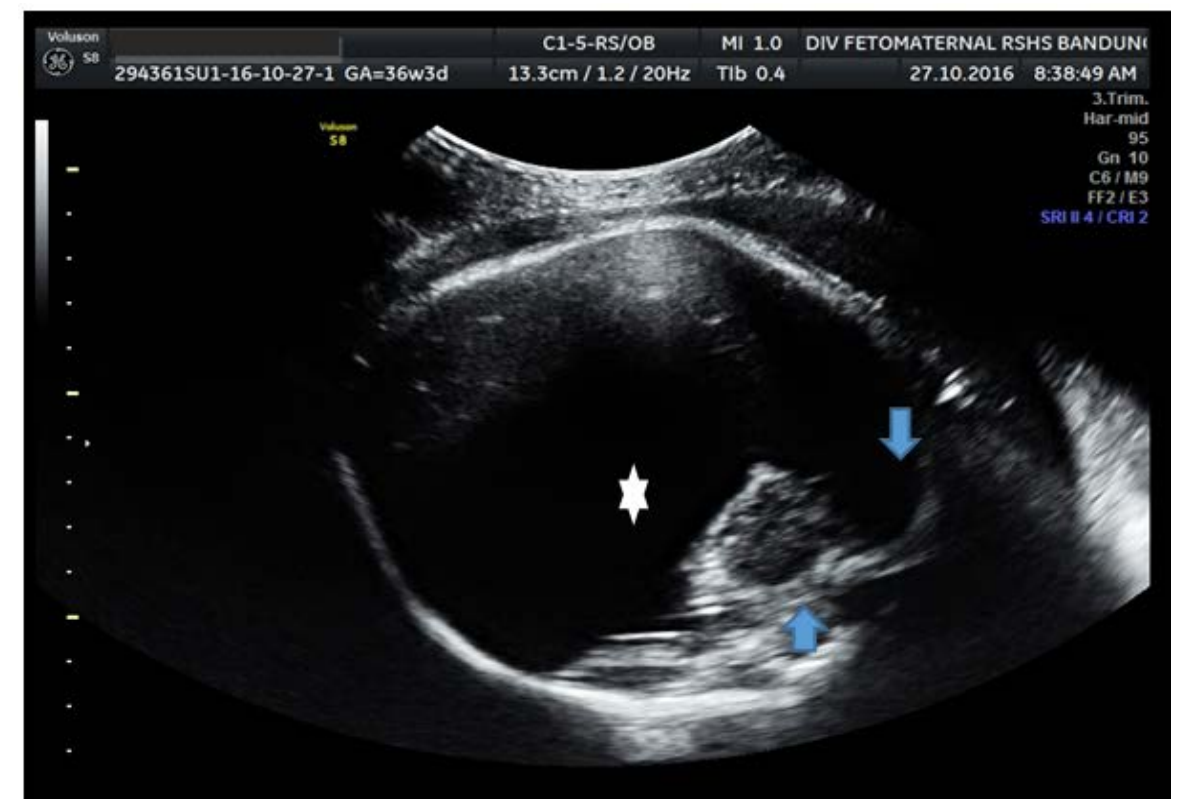

Figure 1. Alobar holoprosencephaly. A coronal image of head demonstrating a large monoventricle ${ }^{*}$ ) above fused thalami (arrows), with no evidences of falx cerebri.

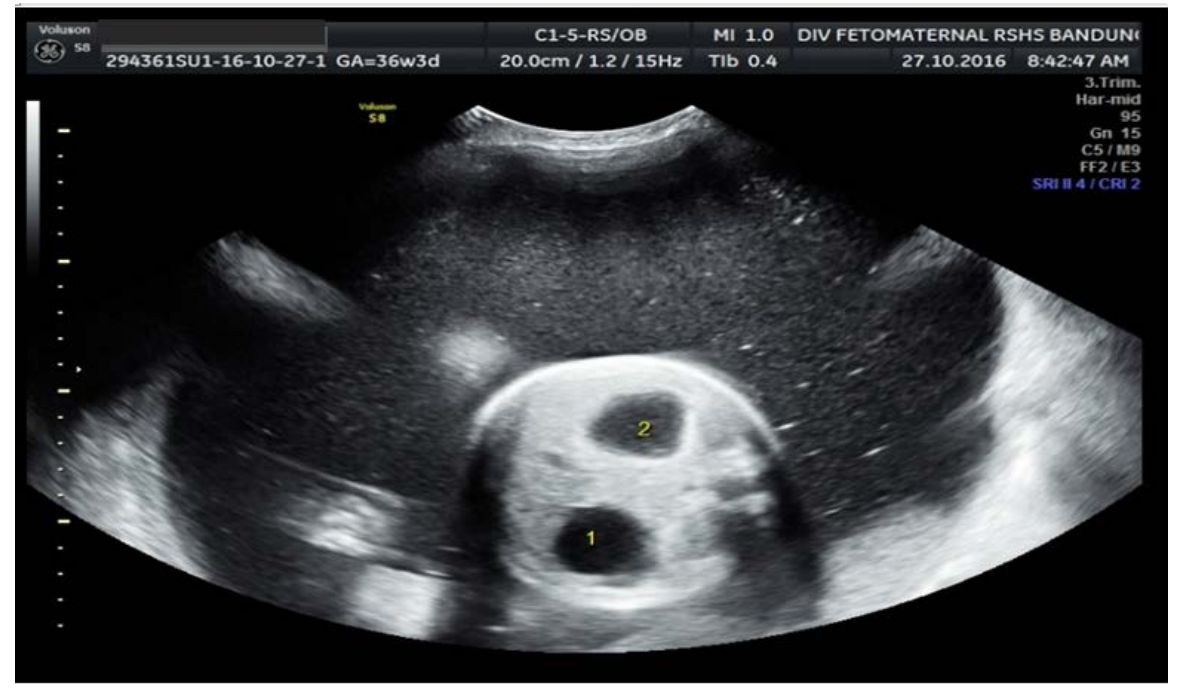

Figure 2. Duodenal atresia, with "double bubble". Transverse view of the fetal upper abdomen demonstrates two fluid filled structure (double bubble), representing the dilated stomach (1) and duodenum (2). Amniotic fluid volume is high.

double bubble on the upper abdomen up to the left and right part. The baby was referred to the pediatric surgery with duodenal atresia and duodenoduodenostomy was planned. Karyotyping laboratory resulted $47 \mathrm{XY}$ and no signs of chromosomal abnormalities.

A male neonate was delivered with birth weight $2650 \mathrm{~g}, \mathrm{~L} 47 \mathrm{~cm}$ and Apgar scores of 7 and 9 at 1 and 5 minutes, respectively. The physical examination revealed facial anomalies (labiopalatognatoschizis, single choana, hypotelorism, absent nasal bone) and abdominal distention (Figure 3 and Figure 4). An 


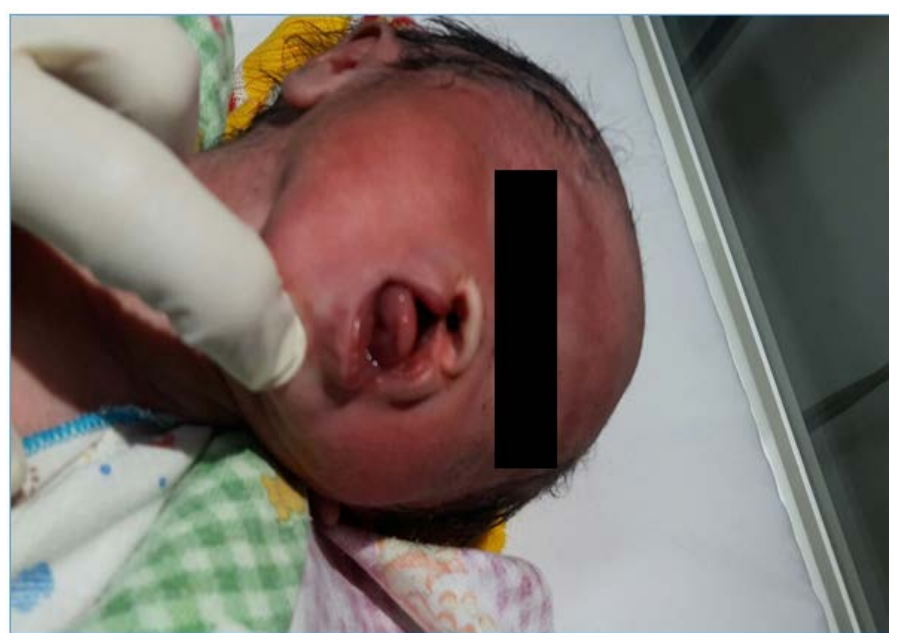

Figure 3. Facial abnormalities (Labiopalatognatoschizis, single choana, absent nasal bone, hypotelorism).

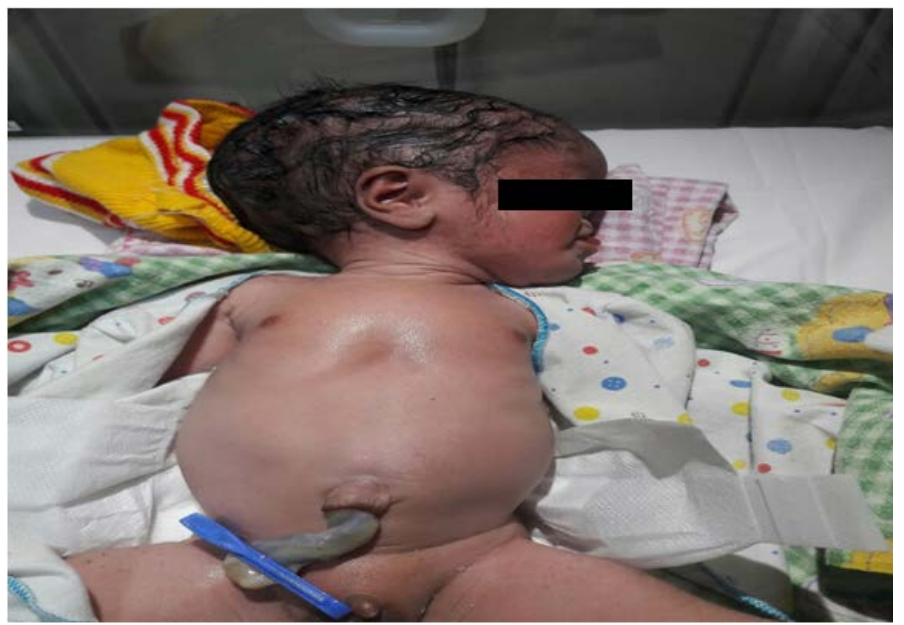

Figure 4. Abdominal distention.

orogastric tube was easily inserted into the stomach, and dark brownies gastric contents were obtained. The radiograph showed double bubble sign. The baby lived up to 3 days, he was given rehydration, fasting and total parenteral nutrition. Mother's condition was good after surgery, without complication. She was hospitalized up to 5 days.

\section{Discussions}

HPE is a developmental anomaly of the brain in which the prosencephalon (forebrain) fails to cleave normally into two cerebral hemispheres. This result incomplete or partial fusion of the cerebral hemispheres and communication of the lateral ventricles across the midline. The falx is underdeveloped or absent. The corpus callosum is usually absent, the thalami may be partially or completely fused [6].

Duodenal atresia is the most common type of fetal small intestinal atresia. The 
pathophysiologic mechanism of duodenal atresia consists of disruption of the patency of the duodenal lumen and failure of canalization, which lead to stenosis or atresia. Duodenal atresia can also be caused by extrinsic compression from a surrounding annular pancreas or peritoneal fibrous band [8].

The frequency of holoprosencephaly is 1 in 10,000 - 20,000 live newborn. During early embryonic period, the frequency is 1 at 250 but progressively declines because of high fetal mortality rates [1] [4]. Duodenal atresia occurs approximately in 1 - 3:10,000 live births [5] [6].

HPE is classified into three types [9] [10]:

1) Alobar, which means the complete absence of division of the prosencephalon structures, resulting in completely absent interhemispheric fissure and corpus callosum, fused thalami, fused cerebral hemispheres with only one cerebral ventricle, and facial dysmorphism which include such as abnormalities cyclopia, proboscis, ethmocephaly and cebocephaly. It is the most severe form.

2) Semilobar, consisting of incomplete separation of the cerebral hemispheres: there are two cerebral hemispheres connected in the frontal area, with a singular ventricular cavity and partially fused thalami.

3) Lobar, in some case interhemispheric fissure is present, septum pellucidum is absent and frontal horns of lateral ventricles communicate freely, corpus callosum is absent hypoplastic or normal, with midline fusion of cingulate gyrus. It is the least severe form.

The etiology of HPE includes genetic and environmental factors. Among the environmental causes there are: maternal diabetes mellitus, maternal alcoholism, in utero infections with CMV, rubella or toxoplasma, some drugs (retinoic acid, cholesterol synthesis inhibitors). HPE can be transmitted in an autosomal dominant way. Mutation of SHH gene is the most frequent cause of familial HPE. Many single gen disorders (18\% - 25\%) can result in syndromes with a variable incidence of HPE. Examples include Pallister Hall, Smith-Lemli-Opitz, pseudotrisomy 13, Rubinstein Taybi, Hydrolethalus and microtia-anotia syndromes [2] [3].

The latest case report of alobar holoprosencephaly was reported by Ionescu et al. (2018), that the case of alobar holoprosencephaly associated with rare chromosomal abnormality. In this case, the fetal had microcephalic condition, very rare chromosomal abnormality $(45 \mathrm{X} / 46, \mathrm{XX} / 47, \mathrm{XX})$ with mosaicism at chromosome 18, single nostril and ethmocephaly [11]. HPE may be associated with a range of craniofacial abnormalities including cyclopia, microcephaly, hypotelorism, depressed nasal bridge, single maxillary incisor and midline cleft lip with or without cleft palate [5]. Moreover, $40 \%$ cases HPE is associated with numerical chromosomal anomalies, such as the most frequent one being trisomy 13 (in about $40 \%$ of cases) and trisomy 18 [2] [3].

Some affected individuals also have pituitary dysfunction and feeding difficulties. The HPE phenotype is variable among simplex cases and among members of the same family with an inherited form of HPE; consequently, subtle facial features may be overlooked in mildly affected family members. Associated 


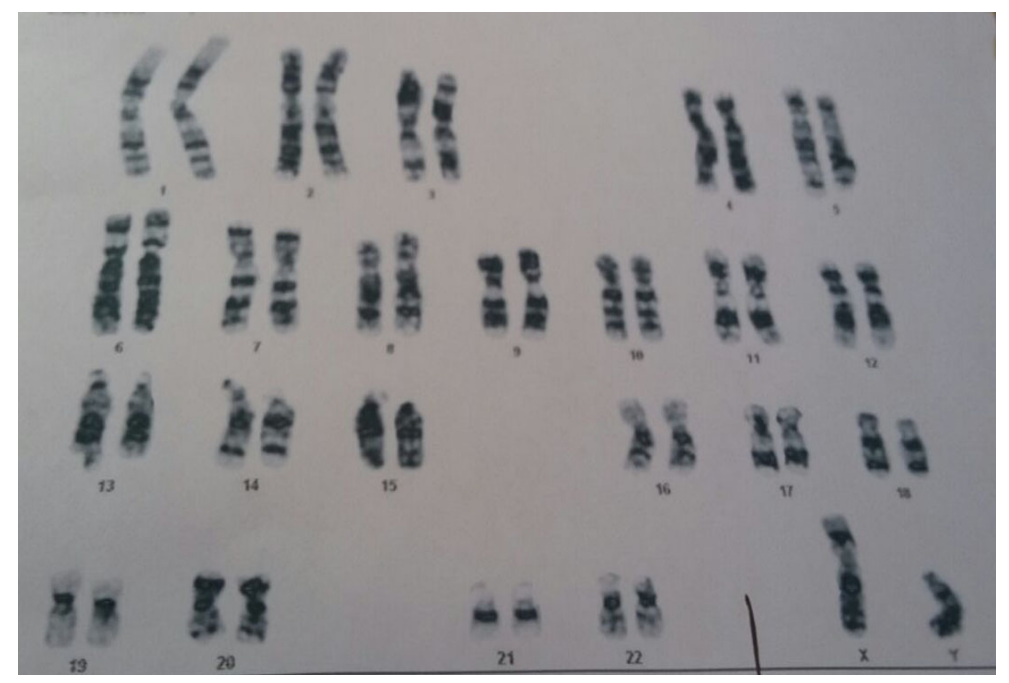

Figure 5. Normal Karyotype 46, XY.

anomalies: nearly half of intestinal atresia cases have an associated abnormality. Trisomy 21 is present in up to $30 \%$ of duodenal atresia cases. The others are Congenital heart defect (e.g. ASD and VSD), malrotation, meconium ileus and peritonitis, esophageal atresia, annular pancreas, genitourinary malformations, anorectal atresia, ventral wall defects and skeletal defects [5]. The risk factor in this case might be the bad environmental condition with polluted water.

With congenital duodenum obstruction, the stomach and proximal duodenum are markedly dilated, which account for the double bubble identification on roentgenogram after birth and which may be identified antenatally by ultrasound. Another prenatal marker is polyhydramnion which occurs in approximately half of the cases due to inability of the fetus to absorb the swallowed amniotic fluid.

After birth, the preferred imaging study for the diagnosis and classification of holoprosencephaly is cranial magnetic resonance imaging (MRI). Other imaging modalities are ultrasonography and cranial computed tomography (CT) scanning. Treatment in severe form of HPE is symptomatic and supportive and requires a multidisciplinary management. Child outcomes depend on the HPE severity and the medical and neurological complications associated.

At present the genetic examination in Hasan Sadikin Hospital is limited up to karyotyping phase, not the sequential association of gen with HPE. During the last decade only few combinations of unsure ectoderm and mesoderm anomalies were reported in Hasan Sadikin Hospital (Figure 5).

\section{Conclusion}

Alobar holoprosencephaly is a disorder of brain development with a very poor prognosis. Combination of alobar holoprosencephaly and duodenal atresia disorders is rare. It might be diagnosed early through appropriate prenatal care and ultrasound examination. The etiology of holoprosencephaly is variable, due to environmental, infection, teratogenic, and genetic factors. The parents should be 
informed since early about the poor prognosis of holoprosencephaly and the best treatment or procedure to be chosen.

\section{Conflicts of Interest}

Authors declare no conflict of interest. The patient had given her consent to authors for the case report to be published.

\section{References}

[1] Abubakar, A., Sanusi, M.I., Ahidjo, A. and Tahir, A. (2014) Alobarholoprosencephaly with Unfused Thalami: A Rare Variety of Holoprosencephaly. International Journal of Case Reports and Images, 5, 756-760. https://doi.org/10.5348/ijcri-2014131-CR-10442

[2] Poenaru, M.O., Lonut, D.V. and Marin, A. (2012) Holoprosencephaly: Two Case Reports. Maedica. A Journal of Clinical Medicine, 7, 58-62.

[3] Levey, E.B., Stashinko, E., Clegg, N.J. and Delgado, M.R. (2010) Management of Children with Holoprosencephaly. American Journal of Medical Genetics, 154, 183-190. https://doi.org/10.1002/ajmg.c.30254

[4] Geng, X. and Oliver, G. (2009) Pathogenesis of Holoprosencephaly. Journal of Clinical Investigation, 119, 1403-1413. https://doi.org/10.1172/JCI38937

[5] Creasy, R.K., Resnik, R., Iams, J.D., Lockwood, C.J., Moore, T.R. and Greene, M.F. (2014) Holoprosencephaly. In: Maternal Fetal Medicine, 7th Edition, Philadelphia, 241-244.

[6] Trojano, G., Battini, L., Bottone, P., Tosi, V., Nanini, C., Carmignani, A., et al. (2014) Duodenal Atresia and Sudden Fetal Death. Running Head: Prenatal Diagnosis of Fetal Duodenal Atresia and Risk of Fetal Adverse Outcome. International Journal of Gynecology \& Obstetrics, 26, 41-42.

[7] Doubilet, P.M. and Benson, C.B. (2012) Holoprosencephaly. In: Atlas of Ultrasound in Obstetrics and Gynecology, 2nd Edition, Philadelphia, 60-62.

[8] Pariente, G., Landau, D., Aviram, M. and Hershkovitz, R. (2012) Prenatal Diagnosis of a Rare Sonographic Appearance of Duodenal Atresia. Journal of Ultrasound in Medicine, 31, 1829-1833. https://doi.org/10.7863/jum.2012.31.11.1829

[9] Woodward, K.S. and Byrne, P. (2016) Alobar Holoprosencephaly. In: Diagnostic Imaging, 3rd Edition, Elsevier, Philadelphia, 118-121.

[10] Cunningham, S. (2014) Fetal Imaging. In: Cunningham, L., Bloom, S., Dashe, H., et al., Eds., Williams Obstetrics, 24th Edition, New York, 194-227.

[11] Ionescu, C.A., Calin, D., Navolan, D., Matei, A., Dimitriu, M., Herghelegiu, C. and Ples, L. (2018) Alobar Holoprosencephaly Associated with Rare Chromosomal Abnormality: Case Report and Literature Review. Medicine, 97, e11521.

https://doi.org/10.1097/MD.0000000000011521 